Revista Brasil. Bot., V.31, n.2, p.227-235, abr.-jun. 2008

\title{
Estudos morfológicos de frutos, sementes e plântulas de Enterolobium schomburgkii Benth. (Leguminosae-Mimosoideae) ${ }^{1}$
}

\author{
MICHELE BRAULE PINTO RAMOS ${ }^{2,3}$ e ISOLDE DOROTHEA KOSSMANN FERRAZ2
}

(recebido: 01 de junho de 2006; aceito: 17 de abril de 2008)

\begin{abstract}
Morphological studies of Enterolobium schomburgkii Benth. (Leguminosae-Mimosoideae) fruits, seeds and seedlings). Enterolobium schomburgkii Benth. ("orelha-de-macaco") is a valuable shade intolerant timber species, because it produces nodules, it has a great potential for plantation in degraded areas. The objective of this propagation study was to describe morphologically fruits, seeds and seedlings and define the "normal seedling" of E. schomburgki in order to provide important information for the development of seed technology. The fruit is a nutant legume, sub woody, polyspermic, with strombus and circular form. The dimensions of the fruit are $21.2 \times 3.2 \mathrm{~cm}$ as extended legume and $6.2 \times 5.9 \times 0.5 \mathrm{~cm}$ in original form. Fresh weight of fruit averaged $6.7 \mathrm{~g}$, with 16.1 healthy seeds per fruit; 62 fruits contain 1,000 healthy seeds. The number of fruit per kilogram was 18,749 and the weight of 1,000 seeds was $53.6 \mathrm{~g}$. The seed is elliptic, with soft surface, brightness, dark yellowish brown, with size of $8.0 \times 3.9 \times 2.6 \mathrm{~mm}$ and fresh weight averaging $0.054 \mathrm{~g}$. The embryonic axis is rectilinear and visible, with plumule well developed. The germination is epigeous phanerocotyledonary, with foliaceous cotyledons. Root protrusion averaged 95.7\%, and 80.2\% for normal seedling formation. The "normal seedling" was developed 7 to 15 days after sowing, with primary root well developed, secondary roots small, long hypocotyl, semi-open cotyledons and first leaf visible, with the same size of cotyledons.
\end{abstract}

Key words - batibatra, biometry, Central Amazonia, germination morphology, seed technology

RESUMO - (Estudos morfológicos de frutos, sementes e plântulas de Enterolobium schomburgkii Benth. (LeguminosaeMimosoideae)). Enterolobium schomburgkii Benth. (orelha-de-macaco) é uma árvore de interesse madeireiro que possui potencial para plantios florestais em áreas degradadas, por ser heliófila e nodulífera. Os objetivos deste trabalho foram caracterizar morfologicamente os frutos, sementes e plântulas e definir o estádio de desenvolvimento da "plântula normal" de E. schomburgkii, visando fornecer informações valiosas para a padronização dos estudos de propagação da espécie na área de tecnologia de sementes. $\mathrm{O}$ fruto é um legume nucóide, sublenhoso, polispérmico, auriculiforme e circular, com as dimensões de 21,2 $\times 3,2 \mathrm{~cm}$ para o legume estendido; e 6,2 $\times 5,9 \times 0,5 \mathrm{~cm}$ para o fruto na forma original. O peso fresco de um fruto foi de $6,7 \mathrm{~g}$, com 16,1 sementes sadias por fruto, sendo necessários 62 frutos para obter 1.000 sementes sadias. O número de sementes por quilograma foi de 18.749 e o peso de mil sementes foi de 53,6 g. A semente é elipsóide, de superfície lisa, brilhosa, marrom-amarelo escuro, com as dimensões de $8,0 \times 3,9 \times 2,6 \mathrm{~mm}$ e peso de $0,054 \mathrm{~g}$. O eixo embrionário é reto e visível, com plúmula bem desenvolvida. Observou-se que a germinação é do tipo epígea fanerocotiledonar, com cotilédones foliáceos. A protrusão da raiz primária foi de $95,7 \%$, e para a formação de plântulas normais foi de $80,2 \%$. A "plântula normal" foi formada entre 7 e 15 dias após a semeadura, possuindo raiz primária bem desenvolvida, raízes secundárias curtas, hipocótilo alongado, cotilédones semi-abertos e primeiros eofilos visíveis, com o mesmo comprimento dos cotilédones.

Palavras-chave - Amazônia Central, biometria, morfologia da germinação, orelha-de-macaco, tecnologia de sementes

\section{Introdução}

A descrição e a classificação de frutos, sementes e plântulas fornece informações que podem ser empregadas na identificação das espécies e auxiliam estudos ligados à germinação, armazenamento, teste de qualidade, métodos de cultivo, manejo, conservação da fauna

\footnotetext{
1. Parte da dissertação de mestrado da primeira autora, Programa de Pós-Graduação em Ciências de Florestas Tropicais do Instituto Nacional de Pesquisas da Amazônia.

2. Instituto Nacional de Pesquisas da Amazônia-INPA, Av. André Araújo, 2936 - Petrópolis, Caixa Postal 478, 69083-000 Manaus, AM, Brasil.

3. Autor para correspondência: mbraule@inpa.gov.br
}

silvestre, ecologia, paleobotânica e arqueologia (Gunn 1972, Lima 1985, Barroso et al. 1999).

As características morfológicas da semente e do embrião constituem um critério bastante seguro para a identificação das plantas em nível de espécie, uma vez que para as angiospermas essas estruturas são pouco influenciadas pelo ambiente, além de variar entre as plantas (Bravato 1974). Além disso, a morfologia de plântulas e suas ilustrações fornecem subsídios para facilitar e padronizar a condução dos testes de germinação em laboratório (Silva et al. 1995).

Outro aspecto da morfologia de plântulas está relacionado com a definição do estádio de "plântula normal", descrita como a fase de germinação na qual a 
planta possui todas as suas estruturas em perfeito estádio de desenvolvimento segundo as Regras para Análise de Sementes (Brasil 1992). Essa definição é fundamental para a padronização dos estudos na área de tecnologia de sementes, uma vez que o principal interesse é a obtenção de plantas com alta probabilidade de estabelecimento no campo.

A espécie Enterolobium schomburgkii Benth. (orelha-de-macaco) é natural da Amazônia e possui ampla distribuição geográfica na área neotropical, ocorrendo desde a América Central, Amazônia legal, Nordeste, Sudeste e Sul do Brasil, estendendo-se até a Argentina, Uruguai, Paraguai e Bolívia (Bentham 1876, Mesquita 1990). É uma árvore de 10 a $50 \mathrm{~m}$ de altura e 12 a $80 \mathrm{~cm}$ de DAP, heliófila e uma das leguminosas que fazem associação com bactérias fixadoras de nitrogênio, portanto pode ser recomendada para o reflorestamento em áreas com solos pobres (Allen \& Allen 1981, Mesquita 1990). A madeira possui potencial de exportação, sendo conhecida no mercado externo como batibatra; é indicada para movelaria, construção civil e naval e para a fabricação de papel (Le Cointe 1947, Loureiro et al. 1979, Chichignoud et al. 1990, Gonçalez \& Gonçalves 2001).

O fruto de E. schomburgkii foi descrito por Mesquita (1990), em sua revisão do gênero, como indeiscente, contorcido, de cor castanha a negra e de consistência sublenhosa, com 3-4 cm de diâmetro por 1-3 cm de espessura. $\mathrm{O}$ epicarpo apresenta superfície glabra; o mesocarpo tem consistência fibrosa a lenhosa e coloração castanha; e o endocarpo é esbranquiçado. A semente é elíptica, de coloração amarelo-enxofre, com as dimensões de $0,7 \mathrm{~cm}$ de comprimento por $0,4 \mathrm{~cm}$ de largura. Os cotilédones são planos, carnosos, com eixo embrionário reto, apresentando plúmula bem desenvolvida, multipartida e diferenciada em pinas.

Souza \& Varela (1989) mencionam que as sementes da espécie possuem dormência física causada por impermeabilidade do tegumento à água, sendo necessária a aplicação de tratamentos de quebra de dormência com desponte ao lado oposto à micrópila ou escarificação mecânica com auxílio de esmeril para promover de $99 \%$ a $100 \%$ de germinação.

A germinação de E. schomburgkii foi descrita por Albuquerque (1993) como sendo do tipo epígea, criptocotiledonar. Porém, o tempo necessário para a formação de uma "plântula normal", assim como as características de normalidade e anormalidade, não estão disponíveis na literatura. Estas informações são de fundamental importância tanto para trabalhos na área de tecnologia de sementes quanto para auxiliar a identificação das espécies nos estádios juvenis.
A literatura disponível carece de informações sobre métodos de beneficiamento, quantidade de sementes por fruto, disposição das sementes no fruto, peso dos frutos, além de outras informações de interesse tecnológico.

O objetivo do presente trabalho foi ilustrar e descrever detalhadamente a morfometria dos frutos, sementes e plântulas de Enterolobium schomburgkii Benth.; comparar morfologicamente sementes originadas de diferentes matrizes e anos de frutificação; e definir o estádio de uma "plântula normal", visando a padronização dos estudos de propagação da espécie.

\section{Material e métodos}

Coleta, beneficiamento e armazenamento - Os frutos foram coletados de quatro matrizes de E. schomburgkii, que ocorrem naturalmente no Campus principal do Instituto Nacional de Pesquisas da Amazônia (INPA) em Manaus, Amazonas (coordenadas $03^{\circ} 08^{\prime} \mathrm{S}$ e $60^{\circ} 02^{\prime} \mathrm{W}$ ).

O clima de Manaus é do tipo "Afi”" na classificação de Köppen, pertencendo ao grupo de clima tropical chuvoso, com média anual de precipitação de $2.325 \mathrm{~mm}$, de temperatura de $26,6{ }^{\circ} \mathrm{C}$ e com umidade relativa do ar variando de $84 \%$ a $90 \%$ ao longo do ano (INPE 2003). O solo do campus foi identificado como latossolo amarelo, de textura argilosa.

Os frutos foram coletados embaixo das matrizes, logo após sua dispersão natural, no mês de setembro dos anos de 1999 (matriz A e B), 2000 (matriz C), 2001 (matriz A e D), e 2002 (matriz A). O beneficiamento foi manual, sendo as vagens colocadas dentro de sacos de tecido e quebradas com auxílio de um bastão de madeira, para liberar as sementes. Em seguida, as sementes foram separadas dos restos de frutos com peneira de malha $5 \mathrm{~mm}$.

Alguns frutos e sementes apresentaram pequenos orifícios contendo pequenas larvas próximos ao eixo embrionário que, após seu desenvolvimento deixavam o eixo embrionário completamente destruído. Para minimizar os danos desta infestação, as sementes secas foram colocadas em vidros hermeticamente fechados, no congelador a $-18{ }^{\circ} \mathrm{C}$ por 24 horas. Após a retirada, os vidros permaneceram fechados por uma hora até atingirem temperatura ambiente em laboratório $\left(25 \pm 4{ }^{\circ} \mathrm{C} ; 60 \%\right.$ a $70 \%$ de Umidade Relativa).

$\mathrm{O}$ peso de mil sementes e o número de sementes por quilograma foram determinados segundo as recomendações das Regras para Análise de Sementes (Brasil 1992).

Aspectos morfométricos de frutos e sementes - Os estudos de morfologia externa e interna dos frutos foram realizados imediatamente após dispersão natural, com 30 unidades provenientes da matriz A, em setembro de 2002. A caracterização das sementes foi realizada com uma amostra de 100 sementes proveniente de cada uma das matrizes utilizadas neste estudo.

As seguintes características foram observadas nos frutos: coloração (seguindo o guia de cores de Munsell Color 
Company 1954), dimensões, textura e consistência do pericarpo, deiscência, número de sementes por fruto, número de sementes normais e anormais e número de sementes predadas. Para as sementes, as características observadas foram coloração (Munsell Color Company 1954), textura e consistência do tegumento, forma da semente e de sua borda, posição do hilo, micrópila e rafe. Internamente observou-se os cotilédones, o eixo embrionário e a plúmula. As sementes foram escarificadas e hidratadas durante 24 horas para facilitar o estudo da morfologia interna.

As medições foram realizadas com auxílio de uma fita métrica, para o comprimento do legume e, para as demais medições utilizou-se um paquímetro digital de precisão 0,01 mm. As dimensões dos frutos foram tomadas conforme o esquema apresentado na figura 1A. As observações da morfologia interna foram realizadas com auxílio de uma lupa de mesa e lupa bilocular com aumento de 10 x. O peso de frutos e sementes foi medido individualmente, utilizandose balança com precisão de $0,001 \mathrm{~g}$.

A terminologia empregada para a descrição de frutos e sementes, foi baseada nos estudos de Ferri et al. (1981), Joly (1993) e Barroso et al. (1999).

Germinação e plântulas normais - O processo germinativo de 30 sementes foi observado diariamente, desde a protrusão da raiz primária (três dias) até o desenvolvimento dos primeiros eofilos (15 dias). A dormência tegumentar foi superada por um desponte no lado oposto ao da protrusão da raiz primária, conforme recomendações de Souza \& Varela (1989). A germinação foi realizada à temperatura constante de $30 \pm 2{ }^{\circ} \mathrm{C}$, em câmara da marca Fanem ${ }^{\circledR}$, com fotoperíodo de 12 horas e radiação fotossinteticamente ativa de aproximadamente $10 \mu \mathrm{mol} \mathrm{m} \mathrm{m}^{-1} \mathrm{~s}^{-1}$. Utilizou-se papel de filtro umedecido, em caixas plásticas transparentes (gerbox), com as dimensões de $11 \times 11 \times 3 \mathrm{~cm}$.

Foi observado o tempo necessário para a protrusão da raiz primária, e a formação da plântula; as características vegetativas descritas e ilustradas foram raiz, coleto, hipocótilo, cotilédones, epicótilo, eofilos; foram medidos comprimento da raiz, diâmetro do coleto, altura e diâmetro do hipocótilo, comprimento, largura e espessura do cotilédone; e observada a abertura dos eofilos e o desenvolvimento do meristema apical.

A terminologia empregada para a descrição do processo germinativo e dos caracteres morfológicos da plântula, foi baseada em Duke (1969), Ferri et al. (1981) e Oliveira (1993).

\section{Resultados e discussão}

Testes físicos e germinação - O peso fresco de um fruto foi de $6,7 \mathrm{~g}$, variando de 4,1 $\mathrm{g}$ até 11,6 $\mathrm{g}$ (tabela 1). Estes resultados indicam certa variação quanto ao peso unitário dos frutos dessa espécie. O número de sementes sadias por fruto foi em média de 16 sementes, variando de 4 a 22 sementes (tabela 2). Os frutos apresentaram de 0 a 10

Tabela 1. Morfometria dos frutos de Enterolobium schomburgkii recém coletados da árvore matriz A em setembro de 2002 $(n=30)$.

Table 1. Morphometry of Enterolobium schomburgkii fresh fruits collected from mother tree A in September $2002(n=30)$.

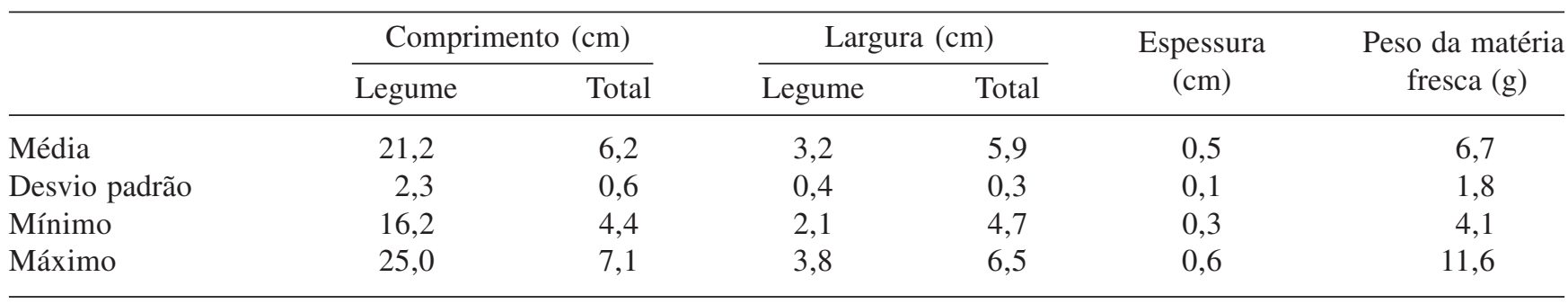

Tabela 2. Número de sementes sadias, não desenvolvidas e atacadas por patógenos por fruto de Enterolobium schomburgkii recém coletados da árvore matriz A em setembro de $2002(n=30)$.

Table 2. Number of healthy, not formed and predated seeds in Enterolobium schomburgkii fresh fruits collection from mother tree A in September $2002(n=30)$.

\begin{tabular}{lcccc}
\hline \multirow{2}{*}{ Medidas } & $\begin{array}{c}\text { Peso fresco do } \\
\text { fruto }(\mathrm{g})\end{array}$ & Sadias & Não desenvolvidas & Atacadas \\
\cline { 3 - 5 } & 4,08 & 4 & 0 & 0 \\
Mínimo & 11,61 & 22 & 10 & 14 \\
Máximo & $6,77 \pm 1,83$ & $16,1 \pm 4,17$ & $2,8 \pm 2,69$ & $2,8 \pm 2,83$ \\
Média \pm Desvio padrão & &
\end{tabular}


sementes não desenvolvidas, com média de 2,8 sementes e desvio padrão de 2,69. Entre 0 a 14 sementes por fruto apresentavam seu embrião destruído pelo ataque de insetos. Assim, para obter 1.000 sementes sadias foi necessário coletar 62 frutos, ou o equivalente a $420 \mathrm{~g}$ de frutos.

O número de sementes por quilograma variou entre 17.109, para sementes provenientes da matriz C, coletadas em setembro de 2000, a 20.279 sementes coletadas em setembro de 2001 da matriz A (tabela 3 ). O valor médio para o número de sementes por quilograma foi de 18.749 sementes, sendo menor do que os resultados apresentados por Souza \& Varela (1989), que mencionam 21.607 sementes de E. schomburgkii por quilograma.

O peso de mil sementes variou entre 49,3 g, para sementes coletadas em setembro de 2001 da matriz A, e
$58,5 \mathrm{~g}$, para sementes coletadas em setembro de 2000 da matriz C (tabela 3). O peso de mil sementes foi em média de 53,6 g, acima dos apresentados por Souza \& Varela (1989), 46 g. A produção de sementes pode ser afetada por características genéticas e por condições ambientais durante seu processo de formação, resultando em variações entre lotes de diferentes anos de frutificação e provenientes de diferentes matrizes de coleta, como mencionado por alguns autores (Figliolia \& Aguiar 1993).

A germinação foi facilmente obtida após desponte das sementes das quatro matrizes e proporcionou altas porcentagens, entre $92 \%$ e $100 \%$ para a protrusão da raiz primária aos 3-5 dias, e entre $73 \%$ e $100 \%$ para a formação de plântulas normais aos 13-15 dias. Estes resultados aproximam-se dos encontrados para esta

Tabela 3. Número de sementes por quilograma e peso de mil sementes (g) de Enterolobium schomburgkii provenientes das árvores matrizes A e B (setembro de 1999), C (setembro de 2000), A (setembro de 2001), D (setembro de 2001) e A (setembro de 2002).

Table 3. Number of seeds per kilogram and weight of 1000 Enterolobium schomburgkii seeds (g) from mother trees A and B (September 1999), C (September 2000), A (September 2001), D (September 2001) and A (September 2002).

\begin{tabular}{lcccccr}
\hline \multirow{2}{*}{ Características } & \multicolumn{7}{c}{ Ano de coleta/matriz } \\
\cline { 2 - 7 } & $1999 / \mathrm{A} \mathrm{e} \mathrm{B}$ & $2000 / \mathrm{C}$ & $2001 / \mathrm{A}$ & $2001 / \mathrm{D}$ & 2002/A & Média \\
\hline Número de sementes kg-1 & 19.564 & 17.109 & 20.279 & 17.687 & 18.047 & 18.749 \\
Peso de mil sementes (g) & 51,1 & 58,4 & 49,3 & 56,5 & 55,4 & 53,6 \\
\hline
\end{tabular}

espécie nos estudos de Souza \& Varela (1989), que apresentaram valores para a formação de plântulas normais iguais a $100 \%$.

Aspectos morfológicos dos frutos - O fruto de $E$. schomburgkii é um legume nucóide longo, achatado, com base e ápice arredondados (figura 1A-D). O pedúnculo é persistente e de consistência lenhosa. A margem do fruto é ondulada, possuindo uma linha de sutura na porção ventral a partir do pedúnculo até o ápice. A porção ventral é mais alongada que a dorsal, assim o fruto forma uma espiral que o torna auriculiforme e circular. Esta característica pode ter inspirado seu nome popular, orelha-de-macaco. A forma irregular dificulta a medição do fruto, bem como a padronização das medições, tornando necessária a descrição detalhada deste procedimento. O fruto é do tipo legume nucóide, sublenhoso e polispérmico. O pericarpo é diferenciado em epicarpo, mesocarpo e endocarpo. O epicarpo apresenta superfície glabra, como também observado por Mesquita (1990). A coloração é marrom-escura a quase negra (dark yellowish brown, 10YR 2/1, segundo o guia de cores de Munsell Color Company 1954), opaca, com elevações ao redor do lóculo seminífero. O mesocarpo é indistinto, como também observado por Barroso et al. (1999), de coloração marrom-amarelada (10YR 4/4, Munsell Color Company 1954) e fibrosa. Internamente, os frutos possuem cavidades transversais onde alojam-se as sementes, lóculo seminífero. As sementes encontram-se ligadas ao fruto na porção ventral, através de um funículo longo e contorcido.

Os frutos de E. schomburgkii apresentaram, em média, 21,2 cm de comprimento por 3,2 cm de largura; e $6,2 \mathrm{~cm}$ de comprimento, por $5,9 \mathrm{~cm}$ de largura, por $0,5 \mathrm{~cm}$ de espessura total (tabela 1). Esses resultados concordam com os registrados por Mesquita (1990) quanto à largura do fruto, entre $3 \mathrm{a} 4 \mathrm{~cm}$. Porém, foram diferentes quanto à espessura, que havia sido registrada entre 1 a $3 \mathrm{~cm}$. Por outro lado, os estudos de Mesquita (1990) não indicam como as medidas foram tomadas. Portanto, a discordância entre os resultados pode ser decorrente da diferença na metodologia utilizada, e não necessariamente a uma variação no tamanho do fruto. 

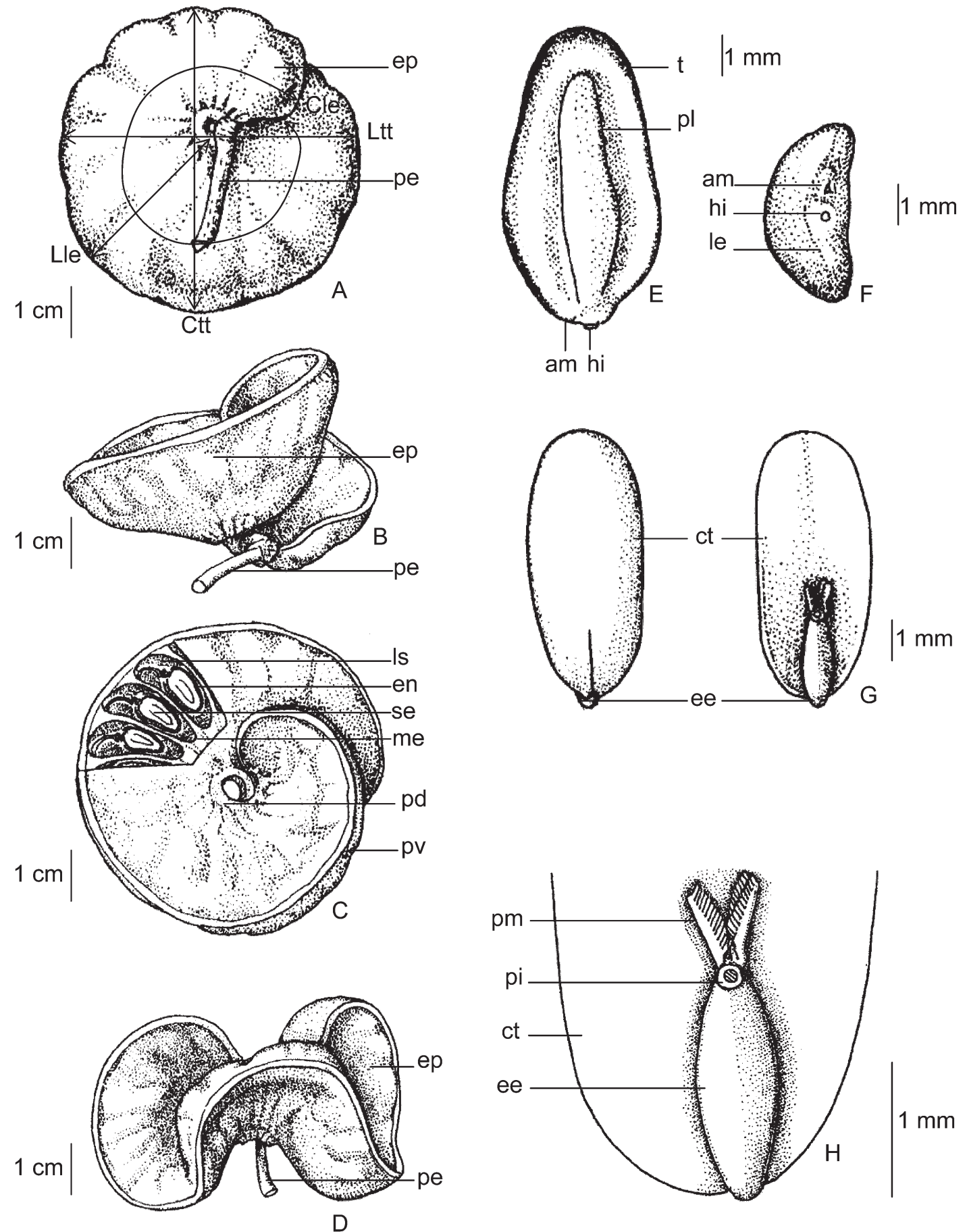

Figura 1. Fruto e semente de Enterolobium schomburgkii coletados em setembro de 2002, matriz A. A, B, C e D. Fruto. E e F. Aspecto externo da semente. G. Embrião. H. Detalhe do eixo embrionário. $(\mathrm{Cle}=$ comprimento do legume; $\mathrm{Ctt}=$ comprimento total; $\mathrm{Lle}=$ largura do legume; $\mathrm{Ltt}=$ largura total; $\mathrm{am}=$ área da micrópila; $\mathrm{ct}=$ cotilédone; ee = eixo embrionário; en = endocarpo; $\mathrm{ep} \mathrm{=} \mathrm{epicarpo;} \mathrm{hi} \mathrm{=} \mathrm{hilo;} \mathrm{le} \mathrm{=} \mathrm{lente;} \mathrm{ls} \mathrm{=} \mathrm{lóculo} \mathrm{seminífero;} \mathrm{me} \mathrm{=} \mathrm{mesocarpo;} \mathrm{pd} \mathrm{=} \mathrm{porção} \mathrm{dorsal;}$ $\mathrm{pe}=$ pedúnculo; $\mathrm{pi}=$ ponto de inserção $; \mathrm{pl}=$ pleurograma $; \mathrm{pm}=$ plúmula $; \mathrm{pv}=$ porção ventral $; \mathrm{se}=$ semente $; \mathrm{t}=$ tegumento).

Figure 1. Fruit and seed of Enterolobium schomburgkii collected in September 2002, from mother tree A. A, B, C and D. Fruit. E and F. Seed. G. Embryo. H. Detail of embryo axis. (Cle = length of legume; $\mathrm{Ctt}=$ total length; Lle $=$ width of legume; $\mathrm{Ltt}=$ total width; $\mathrm{am}=$ micropyle area $\mathrm{ct}=$ cotyledon $;$ ee = embryo axis; $\mathrm{en}=$ endocarp $;$ ep = epicarp; hi = hilum; $\mathrm{le}=$ lens $; \mathrm{ls}=$ seminiferous locule; $\mathrm{me}=$ mesocarp $; \mathrm{pd}=$ surface dorsal; $\mathrm{pe}=$ peduncle; $\mathrm{pi}=$ insertion point; $\mathrm{pl}=$ pleurogram; $\mathrm{pm}=$ plumule; $\mathrm{pv}=$ surface ventral; $\mathrm{se}=$ seed $; \mathrm{t}=$ tegument $)$. 
Aspectos morfológicos das sementes - A semente de $E$. schomburgkii apresenta forma elipsóide ou ovóide, de ápice arredondado e base levemente arredondada, afinada ou obtusa (figura 1E-F). Sua forma elipsóide ou ovóide também foi mencionada por Barroso et al. (1999). A testa tem consistência óssea quando desidratada. A semente possui impresso nas duas faces um pleurograma apical-basal, como também foi descrito por Barroso et al. (1999), ocupando cerca de $90 \%$ do seu comprimento. A sua superfície é lisa, brilhosa, de coloração marromamarelada escura (10YR 4/4, Munsell Color Company 1954), com exceção da área delimitada pelo pleurograma que possui coloração marrom-amarela mais escura (10YR 3/4, Munsell Color Company 1954). A região hilar é da mesma coloração da semente, com hilo circular, localizado na base da semente em leve protuberância (figura 1E-F). A micrópila é imperceptível, sendo possível visualizar a área micropilar. A lente está localizada em leve proeminência ao lado do hilo. O embrião tem coloração verde-claro, com cotilédones oblongos, levemente plano convexos, crassos e dominantes (figura $1 \mathrm{G})$. A base dos cotilédones apresenta uma fenda com cerca de $2 \mathrm{~mm}$ de comprimento em cuja extremidade está localizado o ponto inserção destes no eixo embrionário. O eixo embrionário é reto e visível, como também foi mencionado por Mesquita (1990) (figura 1G-H). O pólo radicular é arredondado e a plúmula bem desenvolvida, com duas folhas diferenciadas em pinas. $\mathrm{Na}$ espécie E. contortisiliquum, a plúmula não é bem desenvolvida na semente não germinada, sendo que a diferenciação dos primeiros eofilos ocorreu somente após 26 dias da semeadura (Oliveira, 1999).

As sementes coletadas ao longo de quatro anos apresentaram com maior freqüência as dimensões de 7,8 a $8,2 \mathrm{~mm}$ de comprimento, 3,7 a $3,9 \mathrm{~mm}$ de largura e 2,4 a $2,5 \mathrm{~mm}$ de espessura (figura $2 \mathrm{~A}-\mathrm{M}$ ). Essas dimensões são similares às observadas por Mesquita (1990), que foram de $7 \mathrm{~mm}$ de comprimento por $4 \mathrm{~mm}$ de largura. Este autor não mencionou a espessura da semente, indicando que esta dimensão foi equivalente à largura das sementes utilizadas no seu estudo. A variação observada através da comparação entre as sementes coletadas em diferentes anos com relação à largura e espessura evidenciou a necessidade de tomar essas medidas separadamente. Desta forma, sementes coletadas em 1999 (Matriz A + B) apresentaram 7,7 mm de comprimento, 3,7 $\mathrm{mm}$ de largura e 2,7 $\mathrm{mm}$ de espessura (figura $2 \mathrm{~A}, \mathrm{E}, \mathrm{I}$ ), enquanto sementes coletadas em 2000 (Matriz C) tiveram resultados de 8,4, 4,2 e 2,4 mm para as mesmas medidas (figura $2 \mathrm{~B}, \mathrm{~F}, \mathrm{~J}$ ). As sementes coletadas em 2001 (Matriz A), apresentaram 7,6, 3,6 e
2,6 mm (figura $2 \mathrm{C}, \mathrm{G}, \mathrm{L}$ ), e as coletadas em 2002 (Matriz A), 8,2, 4,2 e 2,6 mm (figura 2 D, H, M).

O peso médio de uma semente de E. schomburgkii, considerando-se a média geral dos lotes, foi de $0,054 \mathrm{~g}$, variando de 0,033 a $0,092 \mathrm{~g}$. O teor de água das sementes após entrarem em equilíbrio com as condições de armazenamento $\left(15^{\circ} \mathrm{C}\right.$ de temperatura) foi de $10,1 \%$ em média, com $8,9 \%, 10,0 \%, 9,6 \%$ e $11,7 \%$ para as sementes coletadas nos anos de 1999, 2000, 2001 e 2002, respectivamente. $\mathrm{O}$ teor de água médio das amostras foi similar ao observado por Souza \& Varela (1989) que foi de $10,4 \%$ para as sementes da espécie, demonstrando a existência de conformidade nessa característica. Entretanto, foi observada uma variação para o teor de água entre os lotes de sementes que pode estar relacionada às condições anatômicas, físicas e químicas das sementes provenientes de diferentes árvores matrizes e submetidas a diferentes condições ambientais durante sua formação.

Aspectos morfológicos da germinação e das plântulas normais - Após a hidratação, a semente intumesceu, aumentando seu volume em mais de $25 \%$. A germinação teve início aos 2-3 dias após a semeadura, com a protrusão da raiz primária de coloração esbranquiçada a perolada (figura 3). Durante o alongamento, a raiz primária era axial, delgada, ligeiramente curva, cilíndrica, espessa, glabra e perolada a levemente ferrugínea, alcançando entre 1,5 e 2,5 cm de comprimento aos 7 dias após a semeadura; inicialmente a coifa apresentou-se arredondada, tornandose delgada, cônica e afunilada no ápice, de coloração amarelada a ferrugínea após o rápido alongamento da raiz primária; as raízes secundárias eram esparsas e distribuídas irregularmente, delgadas, tenras, glabras, curtas em forma de acúleos cônicos, ramificadas, de nódulos ausentes, inicialmente esbranquiçadas e tornaramse posteriormente ferrugíneas-claras nas extremidades.

O hipocótilo alongou-se rapidamente, sendo inicialmente curvado até tornar-se reto, cilíndrico, de coloração verde-clara próximo aos cotilédones, atingindo entre 5-7 cm de comprimento aos 7 dias após a semeadura; nesse estádio formou-se uma região pilífera e esbranquiçada na região basal com tricomas simples, curtos e finos, mais concentrados na região próxima aos cotilédones e quase ausentes próximo ao colo, perceptíveis somente sob lupa. Colo visível, perceptível principalmente pela diferença entre os tecidos do hipocótilo e da raiz primária.

Os cotilédones eram opostos, foliáceos, persistentes, verde-escuros em ambas as faces, com nervação evidente, com uma fenda visível na base e, inicialmente, inseridos 

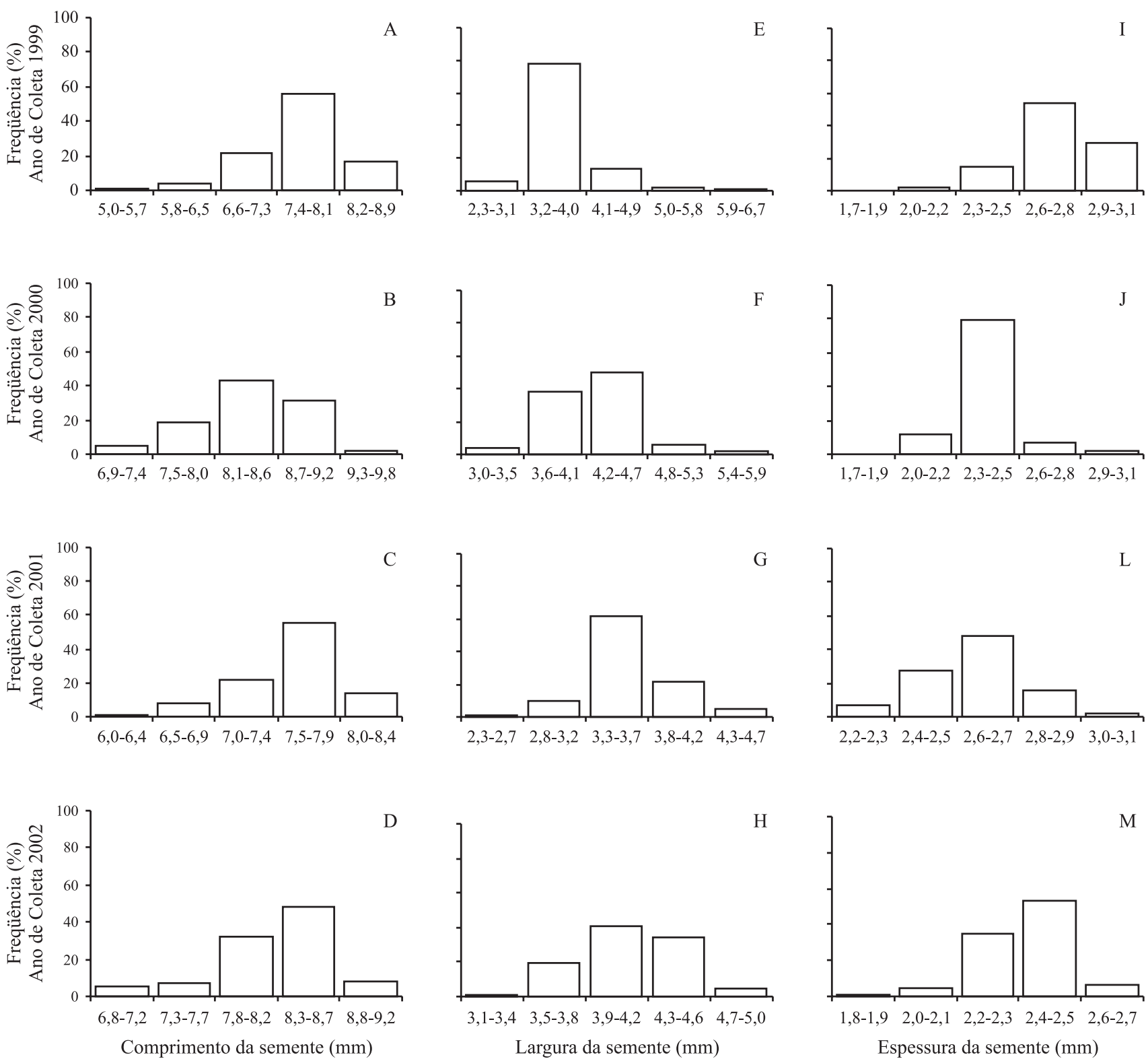

Figura 2. Histogramas de freqüência de comprimento, largura e espessura (mm) de sementes de Enterolobium schomburgkii coletadas em setembro de 1999, 2000, 2001 e 2002 ( $n=100$ por ano de coleta). A, B, C e D. Comprimento da semente (mm). E, F, G e H. Largura da semente (mm). I, J, L e M. Espessura da semente.

Figure 2. Frequency histogram of length, width and thickness (mm) of Enterolobium schomburgkii seeds collected in September 1999, 2000, 2001 and 2002 ( $n=100$ per collection year). A, B, C and D. Seed length. E, F, G and H. Seed width. I, J, L and M. Seed thickness.

no hipocótilo quase verticalmente, passando a semiabertos após 10 dias da semeadura; o epicótilo era pouco alongado, sendo pouco perceptível.

Os primeiros dois eofilos eram opostos, sendo o primeiro composto de uma pina e o segundo de duas pinas. As pinas eram paripinadas, com 11-15 pares de foliólulos verde-claros, membranáceos. Cada foliólulo era assimétrico na base e levemente pontiagudo no ápice, sub-séssil, sem nervações evidentes, possuindo margem inteira e tricomas simples, esparsos, distribuídos irregularmente.

A fase descrita até este ponto foi definida como o estádio de "plântula normal", alcançado aos 7-15 dias após a semeadura (figura 3B). As plantas consideradas 


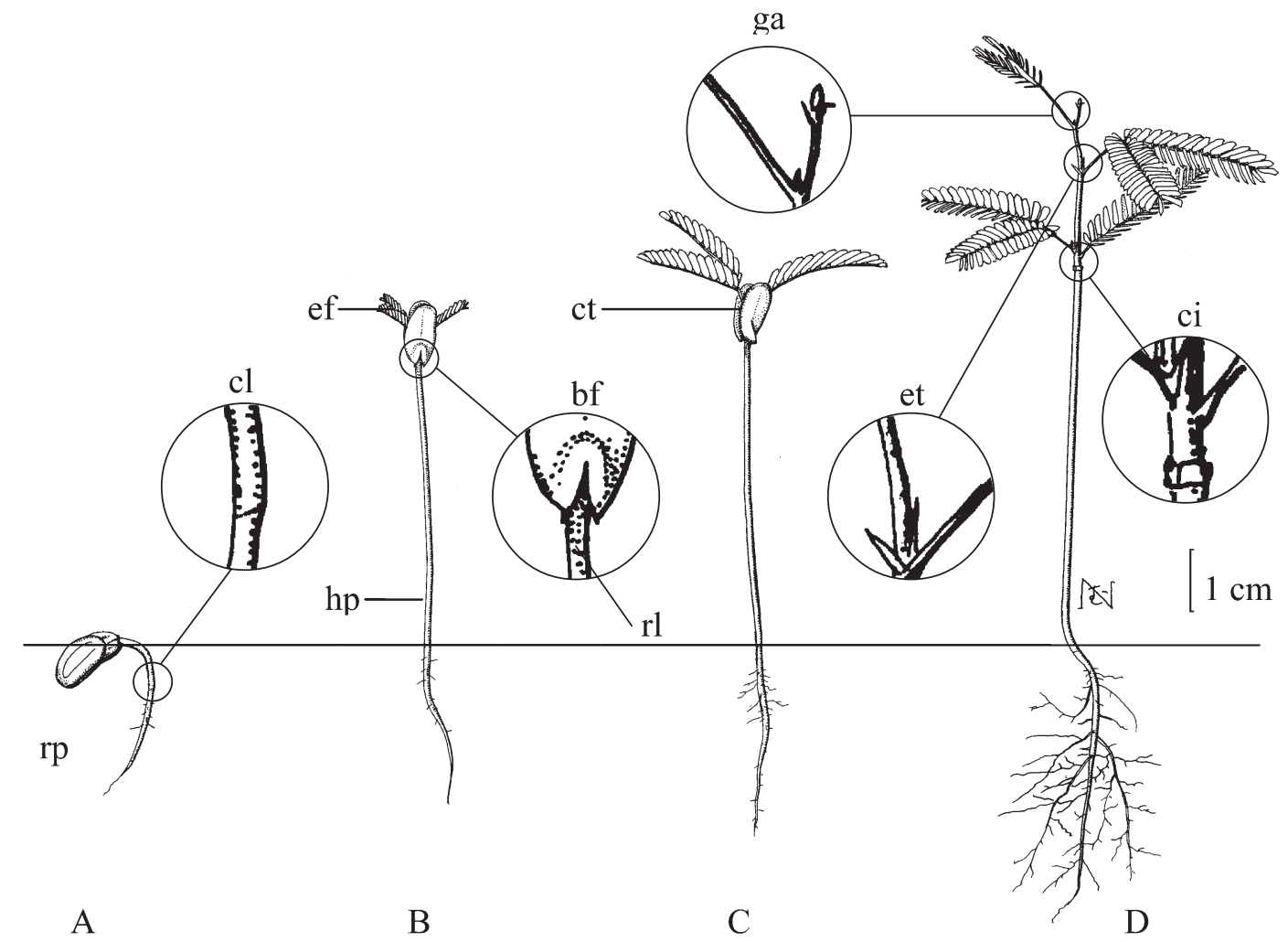

Figura 3. Enterolobium schomburgkii. Estádios de germinação. A. Protrusão da raiz primária aos 3 dias após a semeadura. B. Alongamento da raiz primária e liberação dos cotilédones de dentro do tegumento aos 7 dias após a semeadura. C. Surgimento dos eofilos aos 15 dias após a semeadura. D. Abscisão dos cotilédones. (bf = base fendida; ci = cicatriz cotiledonar; cl = colo; $\mathrm{ct}=$ cotilédone; ef = eofilo; et = estípula; ga = gema apical; hp = hipocótilo; $\mathrm{rl}=$ região pilífera; $\mathrm{rp}=$ raiz primária).

Figure 3. Enterolobium schomburgkii. Germination stages. A. Primary root protrusion three days after sowing. B. Primary root shooting and cotyledon liberation from the tegument seven days after sowing. C. Plumule 15 days after sowing. D. Cotyledon abscision. (bf = fended basys; $\mathrm{ci}=$ cotyledon scar; $\mathrm{cl}=$ colon; $\mathrm{ct}=$ cotyledon; ef = plumule; et = stipule; ga = apical meristem; $\mathrm{hp}=$ hypocotyl; $\mathrm{rl}=$ piliferous region; $\mathrm{rp}=$ primary root).

anormais durante o processo germinativo apresentaram eofilos despigmentados, mesmo após várias semanas; atrofia dos eofilos, hipocótilo ou raiz; e raízes contorcidas.

Após o estádio de "plântula normal", ocorreu a expansão dos eofilos que assumiram tamanho três vezes maior do que os cotilédones após quatro dias (figura 3C). O desenvolvimento das pinas, alternas, em número de duas, ocorreu quase ao mesmo tempo que a abscisão dos cotilédones, aos 16 dias, sendo possível visualizar a cicatriz cotiledonar. Oposta ao par de pinas, formou-se uma estípula bem visível. Nesta fase, observou-se facilmente a gema apical, em forma de cone, afunilada, verde-clara. A raiz primária tomou consistência lenhosa e as raízes secundárias tornaram-se abundantes e ramificadas (figura 3D).

A germinação observada para E. schomburgkii foi do tipo epígea, fanerocotiledonar, considerada por Duke
\& Polhill (1981) a forma de germinação mais comum para a maioria das leguminosas. A classificação da espécie como epígea confirma as observações feitas por Moreira \& Moreira (1996) e Albuquerque (1993). Para a característica fanerocotiledonar, os dados apresentados concordam com Moreira \& Moreira (1996) e discordam de Albuquerque (1993), que descreveu a germinação como criptocotiledonar.

Foi possível descrever e ilustrar detalhadamente a morfologia dos frutos, sementes e germinação da espécie e estabelecer o estádio de "plântula normal", considerando características de fácil reconhecimento, padronização, rápida obtenção e alta probabilidade de estabelecimento no campo. Assim, para fins de avaliação da germinação na área tecnológica recomendou-se considerar a "plântula normal" da espécie E. schomburgkii aos 7-15 dias após a semeadura, possuindo raiz primária bem desenvolvida, 
raízes secundárias curtas, hipocótilo alongado, cotilédones semi-abertos e primeiros eofilos visíveis, com o mesmo comprimento dos cotilédones.

Agradecimentos - Agradecemos ao Conselho Nacional de Desenvolvimento Científico e Tecnológico-CNPq, à Fundação de Amparo à Pesquisa no Estado do Amazonas-FAPEAM e ao Projeto Jacaranda (MCT-INPA/ABC-JICA), pelo apoio parcial à pesquisa, e a esse último pelo financiamento para a ilustração e permissão para a utilização dos desenhos apresentados, realizados por M. Nakajima. Agradecemos ao pesquisador Dr. Niro Higuchi, pela leitura crítica e sugestões, à M. Sc. Maria Auxiliadora Souza e ao técnico agrícola Lúcio Batalha, pelo auxílio na coleta de dados.

\section{Referências bibliográficas}

ALBUQUERQUE, J.M. 1993. Identificação e germinação de sementes amazônicas. Serviço de Documentação e Informação. Faculdade de Ciências Agrárias do Pará, Belém.

ALLEN, O.N. \& ALLEN, E.K. 1981. The leguminosae. A source book of characteristics, uses and nodulation. University of Wisconsin Press, Wisconsin.

BARROSO, G.M., MORIN, M.P., PEIXOTO, A.L. \& ICHASO, C.L.F. 1999. Frutos e sementes: morfologia aplicada à sistemática de dicotiledôneas. Universidade Federal de Viçosa, Viçosa.

BENTHAM, G. 1876. Leguminosae. Mimosoideae. In Flora brasiliensis (C.F.P. Martius \& R.C. Wolf, eds.). F.B. Keller, Monachii, v.15, pars 1, p.456-458.

BRASIL, Ministério da Agricultura e Reforma Agrária, 1992. Regras para análise de sementes. Governo do Brasil, Brasília.

BRAVATO, M. 1974. Estudio morfologico de frutos y semillas de las mimosoideae (Leguminosae) de Venezuela. Acta Botanica Venezuelica 5:317-361.

CHICHIGNOUD, M., DEON, G., DETIENNE, P., PARANT, B. \& VANTOMME, P. 1990. Atlas de maderas tropicales de America Latina. Organización Internacional de las Maderas Tropicales/ Centre Technique Forestier Tropical. Nogent-sur-Mame, Yokohama.

DUKE, J.A. 1969. On tropical tree seedlings. I. Seeds, seedlings, systems and systematics. Annals of the Missouri Botanical Garden 56:125-161.

DUKE, J.A. \& POLHILL, R.M. 1981. Seedlings of Leguminosae. In Advances in Legumes Systematics. (R.M. Polhill \& P.H. Raven, eds.). Royal Botanic Garden, England, v.2, p.941-949.

FERRI, M.G., MENEZES, N.L. \& MONTEIRO, W.R. 1981. Glossário ilustrado de botânica. Nobel, São Paulo.
FIGLIOLIA, M.B. \& AGUIAR, I.B. 1993. Colheita de sementes. In Sementes florestais tropicais. (I.B. Aguiar, F.C.M. Piña-Rodrigues \& M.B. Figliolia, eds.). ABRATES, Brasília, p.275-302.

GONÇALEZ, J.C. \& GONÇALVES, D.M. 2001. Valorização de duas espécies de madeira Cedrelinga catenaeformis e Enterolobium schomburgkii para a indústria madeireira. Brasil Florestal 70:69-74.

GUNN, C.R. 1972. Seed collecting and identification. In Seed biology. (T.T., Kozlowski, ed.). Academic Press, New York, v.3, p.55-143.

INPE, 2003. Climatologias de precipitação e temperatura. Instituto Nacional de Pesquisas Espaciais. Disponível em: <http://www. Cptec.inpe.br/clima/monit/monitor_ brasil.shtml> Acesso em 10 jan. 2003.

JOLY, A.B. 1993. Botânica: introdução à taxonomia vegetal. Editora Nacional, São Paulo.

LE COINTE, P. 1947. Amazônia brasileira III: Arquivo de plantas úteis (indígenas e aclimatadas). 2ª ed. Companhia Editora Nacional, São Paulo.

LIMA, M.P.M. 1985. Morfologia dos frutos e sementes dos gêneros da tribo Mimoseae (Leguminosae-Mimosoideae) aplicada à sistemática. Rodriguésia 37:53-78.

LOUREIRO, A.A., SILVA, M.F. \& ALENCAR, J.C. 1979. Essências madeireiras da Amazônia. v.2, Instituto Nacional de Pesquisas da Amazônia/Superintendência da Zona Franca de Manaus, Manaus.

MESQUITA, A.L. 1990. Revisão taxonômica do Gênero Enterolobium Mart. (Mimosoideae) para a região neotropical. Dissertação de Mestrado, Universidade Federal Rural de Pernambuco, Recife.

MOREIRA, F.M.S. \& MOREIRA, F.W. 1996. Características da germinação de sementes de 64 espécies de Leguminosas florestais nativas da Amazônia, em condições de viveiro. Acta Amazonica 26:3-16.

MUNSELL COLOR COMPANY. 1954. Munsell soil color charts. $1^{\text {st }}$ ed., Munsell Color Company, Baltimore.

OLIVEIRA, D.M.T. 1999. Morfologia de plântulas e plantas jovens de 30 espécies arbóreas de Leguminosae. Acta Botanica Brasilica 13:263-269.

OLIVEIRA, E.C. 1993. Morfologia de plântulas. In Sementes Florestais Tropicais (I.B. Aguiar, F.C.M. Piña-Rodrigues \& M.B. Fogliolia, eds.). ABRATES, Brasília, p.175-214.

SILVA, L.M.M., MATOS, V.P., PEREIRA, D.D. \& LIMA, A.A. 1995. Morfologia de frutos, sementes e plântulas de Luetzelburgia auriculata Ducke (pau-serrote) e Pterogyne nitens Tul. (madeira-nova-do-brejo) Leguminosae. Revista Brasileira de Sementes 17:154-159.

SOUZA, S.G.A. \& VARELA, V.P. 1989. Tratamentos prégerminativos em sementes de faveira-orelha-de-macaco (Enterolobium schomburgkii Benth.). Acta Amazonica 19:19-26. 